\title{
A new cave-dwelling species of Bisetocreagris Ćurčić (Arachnida, Pseudoscorpiones: Neobisiidae) from Yunnan Province, China
}

\author{
Yun-Chun Li, Ai-Min Shi \& Huai Liu*
}

Li, Y.-C., Shi, A.-M. \& Liu, H. 2017: A new cave-dwelling species of Biseto-
creagris Ćurčić (Arachnida, Pseudoscorpiones: Neobisiidae) from Yunnan Pro-
vince, China. - Entomol. Fennica 28: 212-218.

A new pseudoscorpion species, Bisetocreagris xiaoensis Li \& Liu, sp. n., is described and illustrated from specimens collected in caves in Yanjin County, Yunnan Province, China. An identification key is provided to all known cavedwelling representatives of the genus Bisetocreagris in the world.

Y.-C. Li, College of Plant Protection, Southwest University, Beibei, Chongqing 400700, China; E-mail: liyunchun2260@126.com

A.-M. Shi, Key Laboratory of Southwest China Wildlife Resources Conservation, Institute of Rare Animals \& Plants, China West Normal University, Nanchong, Sichuan637009, China; E-mail: aiminshi2003@126.com

H. Liu (*Corresponding author), College of Plant Protection, Southwest University, Beibei, Chongqing 400700, China; E-mail: liuhuai@swu.edu.cn

Received 12 May 2017, accepted 10 July 2017

\section{Introduction}

The pseudoscorpion subfamily Microcreagrinae Balzan belongs to the family Neobisiidae Chamberlin. It is divided into 32 genera with only three genera, Bisetocreagris Ćurčić, 1983, Microcreagris Balzan, 1892 and Stenohya Beier, 1967 having been reported from China (Harvey 2013, Mahnert \& Li 2016).

The genus Bisetocreagris, with Microcreagris annamensi Beier, 1951 (by original designation) (Harvey 2013) as the type species, is characterized by the terminal exterior and interior trichobothria situating near the tip of the distal finger, the sub-terminal exterior trichobothria being isolated in the distal half of the fixed finger, the interior basal, interior sub-basal and interior sub-terminal trichobothria being grouped closely together at the finger base, the exterior basal and exterior sub-basal trichobothria being located on the lateral distal side of the hand, thus five trichobothria are grouped basally (Mahnert \& Li 2016).

At present, the genus Bisetocreagris contains 35 species and 1 subspecies and is widely distributed in Afghanistan, China, India, Japan, Kyrgyzstan, Mongolia, Nepal, Philippines, Pakistan, Russia, Tajikistan, Thailand, Uzbekistan and Vietnam (Harvey 2013, Mahnert \& Li 2016, Guo \& Zhang 2017). So far, 21 species have been reported from China (Table 1, including also the new species described here). Of the species that have been described, most live in leaf litter of forests. However, nine species, the so-called cavernicolous species or troglobites and including the new one described here, are found in China only in few caves currently.

During the identification of pseudoscorpion 
Table 1. Reported 21 species and a new species of Bisetocreagris from China.

\begin{tabular}{|c|c|c|}
\hline Species & Distribution & References \\
\hline B. annamensis (Beier, 1951) & $\begin{array}{l}\text { Xishuangbanna County, } \\
\text { Yunnan Province }\end{array}$ & $\begin{array}{l}\text { Schawaller 1995, } \\
\text { Harvey } 2013\end{array}$ \\
\hline B. baozinensis Mahnert \& Li, 2016 & Gulin County, Sichuan Province & Mahnert \& Li 2016 \\
\hline B. cavernarum Mahnert \& Li, 2016 & Beibei County, Chongqing Province & Mahnert \& Li 2016 \\
\hline B. cheni Jia, Zhao \& Zhu, 2010 & Tonglu County, Zhejiang Province & Harvey 2013, Guo \& Zhang 2017 \\
\hline B. chinacavernicola (Schawaller, 1995) & Huaying County, Sichuan Province & Mahnert \& Li 2016 \\
\hline B. chuanensis Mahnert \& Li, 2016 & Xinhua County, Guizhou Province & Mahnert \& Li 2016 \\
\hline B. indochinensis (Redikorzev, 1938) & $\begin{array}{l}\text { Xishuangbanna County, } \\
\text { Yunnan Province }\end{array}$ & $\begin{array}{l}\text { Schawaller 1995, } \\
\text { Harvey } 2013\end{array}$ \\
\hline B. juanxuae Mahnert \& Li, 2016 & Xinwen County, Sichuan Province & Mahnert \& Li 2016 \\
\hline B. kaznakovi (Redikorzev, 1918) & $\begin{array}{l}\text { Rivière Tshok-tshio and } \\
\text { Monts Amnenkor, Xizang Autonomous Region }\end{array}$ & $\begin{array}{l}\text { Redikorzev 1918, } \\
\text { Guo \& Zhang } 2017\end{array}$ \\
\hline B. kwantungensis (Beier, 1967) & Tsin Leong San, Guangdong Province & Beier 1967, Harvey 2013 \\
\hline B. lampra (Chamberlin, 1930) & Wuyishan County, Fujian Province & Schawaller 1995, Harvey 2013 \\
\hline B. martii (Mahnert, 2003) & Zhenxiong County, Yunnan Province & Mahnert \& Li 2016 \\
\hline B. nankingensis Ćurčić, 1983 & Nanjing County, Jiangsu Province & Schawaller 1995, Harvey 2013 \\
\hline B. orientalis (Chamberlin, 1930) & Linan County, Zhejiang Province & Harvey 2013 \\
\hline B. parva Guo \& Zhang, 2017 & Tonglu County, Zhejiang Province & Guo \& Zhang 2017 \\
\hline B. scaurum (Mahnert, 2003) & Zhenxiong County, Yunnan Province & Mahnert \& Li 2016 \\
\hline B. silvestrii (Chamberlin, 1930) & $\begin{array}{l}\text { Emei County, Sichuan Province; } \\
\text { Huaxi County, Guizhou Province; } \\
\text { Henshan County, Hunan Province; } \\
\text { Linan County, Zhejiang Province }\end{array}$ & $\begin{array}{l}\text { Schawaller 1995, } \\
\text { Harvey } 2013\end{array}$ \\
\hline B. thailandica Schawaller, 1994 & Xishuangbanna County, Yunnan Province & Schawaller 1995, Harvey 2013 \\
\hline B. titanium (Mahnert, 2003) & Zhenxiong County, Yunnan Province & Mahnert \& Li 2016 \\
\hline B. ussuriensis (Redikorzev, 1934) & $\begin{array}{l}\text { Changbai County, Jilin Province } \\
\text { Laiyuan County, Hebei Province }\end{array}$ & $\begin{array}{l}\text { Schawaller 1995, } \\
\text { Harvey } 2013\end{array}$ \\
\hline B. xiaoensis Li \& Liu, sp. n. & Yanjin County, Yunnan Province & This article \\
\hline B. yangae Guo \& Zhang, 2017 & Huangshan County, Anhui Province & Guo \& Zhang 2017 \\
\hline
\end{tabular}

specimens collected from Yunnan Province in 2017, a new cavernicolous species of Bisetocreagris was found, which is described here.

\section{Materials and methods}

The new species was collected by hand from a cave under rocks where the place is very humid. The specimens were conserved in $75 \%$ ethanol. They were cleared in acid lactic for $12-24 \mathrm{~h}$ at room temperature and returned after washing in distilled water to alcohol after examination. The specimens were analyzed with a Leica M205C stereomicroscope and Olympus BX51 general optical microscope.

The measurements are given in $\mathrm{mm}$. Proportions and measurements of pedipalps and cara- pace correspond to length/breadth, those of legs to length/depth. The term "rallum" (for flagellum) is adopted following Judson (2007). The terminology of trichobothria follows Chamberlin (1931) and Harvey (1992), the measurements follow Chamberlin (1931).

The type specimens of the new species as well as all the specimens of the other studied species are deposited in the collections of the Museum of Southwest University (MSWU), Chongqing City, China.

The following abbreviations are used in the text for the trichobothria: $b=$ basal, $e b=$ exterior basal, $e s b=$ exterior subbasal, $i b=$ interior basal, $s b=$ sub-basal, is $b=$ interior sub-basal, $t=$ terminal, et $=$ exterior terminal, $i t=$ interior terminal, $s t$ $=$ sub-terminal, $i s t=$ interior sub-terminal, $e s t=$ exterior sub-terminal. 


\section{Taxonomy}

Family Neobisiidae Chamberlin, 1930

Subfamily Microcreagrinae Balzan, 1892

Genus Bisetocreagris Ćurčić, 1983

\subsection{Material of Bisetocreagris species examined}

B. martii (Mahnert, 2003):1ð and 2q, Yunnan Province, Zhenxiong County, Wude town, Xiao Guo Quan cave, 27²9.712' N, 104 44.678' E, 1,301 m, 9.IV.2017, Yun-Chun Li leg.

B. titanium (Mahnert, 2003): 29 , Yunnan Province, Zhenxiong County, Wude town, Xiao Guo Quan cave, $27^{\circ} 29.712^{\prime} \mathrm{N}, 104^{\circ} 44.678^{\prime} \mathrm{E}$, 1,301 m, 9.IV.2017, Yun-Chun Li leg.

B. baozinensis Mahnert \& Li, 2016: $5 \hat{\jmath}$ and 6우,

Sichuan province, Gulin County, Yuhua town, Bao $\mathrm{Zi}$ cave, $28.01458^{\circ} \mathrm{N}, 106.05209^{\circ}$ E, 954 m, 22.IV.2014, Yun-Chun Li \& YuCheng Lin leg.

B. juanxuae Mahnert \& Li, 2016: $7 \hat{\bigcirc}$ and 13웅, Sichuan province, Xingwen County, Shihai town, Dao cave, $28.18900^{\circ} \mathrm{N}, 105.12118^{\circ} \mathrm{E}$, 840 m, 17.X.2015, Yun-Chun Li leg.; $5 \hat{\jmath}$ and 9옹 Sichuan province, Xingwen County, Shihai town, Tian Yang cave, 28.19094 N, $105.13734^{\circ} \mathrm{E}, 835$ m, 18.X.2015, Yun-Chun Li leg.

B. cavernarum Mahnert \& Li, 2016: $3 \hat{\jmath}$ and 5ㅇ, Chongqing, Beibei, Jindaoxia town, Er Long cave, $30.05539^{\circ} \mathrm{N}, 106.62385^{\circ} \mathrm{E}, 776 \mathrm{~m}$, 8.X.2015, Yun-Chun Li leg.

B. chuanensis Mahnert \& Li, 2016: $2{ }^{\Uparrow}$ and 1ㅇ, Guizhou province, Jinsha County, Xinhua town, Chuan cave, $27^{\circ} 23.797^{\prime} \mathrm{N}, 106^{\circ}$ 06.104' E, 1,387 m, 2.X.2015, Yun-Chun Li leg.

\subsection{Description of Bisetocreagris xiaoensis Li \& Liu, sp. n. (Figs 1-3)}

Type material. Holotype: đ̂, China, Yunnan Province, Yanjin County, Dousha town, Xiao cave, $28^{\circ} 02.405^{\prime} \mathrm{N}, 104^{\circ} 06.845^{\prime} \mathrm{E}, 708 \mathrm{~m}, 11 . \mathrm{IV} .2017$,
Yun-Chun Li leg. Paratypes: $7 \widehat{\jmath}$ and $10 \circ$, same data as holotype.

Diagnosis. Troglobiont habitus. Carapace with 2 indistinct lense (anterior) eyes; carapace with 6 setae on posterior margin, tergite I with 7 setae; chelicera with teeth of movable finger on thickened lamella, rallum with 7-8 blades, the distal one with expanded base. The new species is most similar to B. scaurum (Mahnert, 2003), but can be distinguished (new species vs. B. scaurum) from the pinnate setae of cheliceral rallum (8 vs. 9), chaetotaxy of tergites I (7 vs. 6) and fixed finger of pedipalps (163-171 vs. 105).

Description. Male (Fig. 3a). Colouration: Carapace, pedipalps and chelicera brown, tergites darker, legs slightly yellowish.

Carapace: With 2 (anterior) eyes with indistinct lense, about 3.0-3.5 diameters of the anterior margin; Anterior margin of carapace distinctly narrow (Fig. 1a), 1.21-1.25 longer than broad, epistome a distinct triangle, with sharped apices; chaetotaxy 6:9-10:4-5:6 (25-27), anterolateral setae much shorter than others.

Tergal chaetotaxy: 7:6:6:6:6:7:8:8:9:9:6-8 (2 tactile setae):4. Sternite III with anteromedian groove flanked by one small seta on each side, with 19-20 long setae (5 medial discal setae)+4 6 suprastigmal setae. IV-XII: 16-17:19-20: 18:18:16:16:13-14:3-4 (2 lateral tactile setae):4. Manducatory process rounded, with 5 (4-5 on right side) marginal setae. Pedipalpal coxa with 6-7 setae, two lyrifissures, coxa I 10-11, II 6-7, III 4-5, IV 11-12. Genital operculum of male (Fig. 2h) with 39-48 setae, lateral marginal setae longer than middle ones.

Cheliceral palm (Fig. 2e): 6-7 long, with thin setae, ventrobasal seta shorter than others, palm with moderate hispid granulation dorsally. Fixed cheliceral finger with 13-14 teeth, distal tooth larger than the others; movable finger on the left with 1 (in the middle)-2 setae (in the middle and near distal $1 / 3$ ), on the right only with 1 setae (Fig. 2f), with 11-12 teeth, the medial ones on thickened lamella. Galea (Fig. 2e-f): a short slender transparent rod on left chelicera. Serrula exterior with about 39-43 and serrula interior with 32-36 blades. Rallum composed of 7-8 blades (Fig. 10), distal one separated and with expanded base, proximal one short.

Pedipalps (Fig. 2a-d): Longer and slenderer 

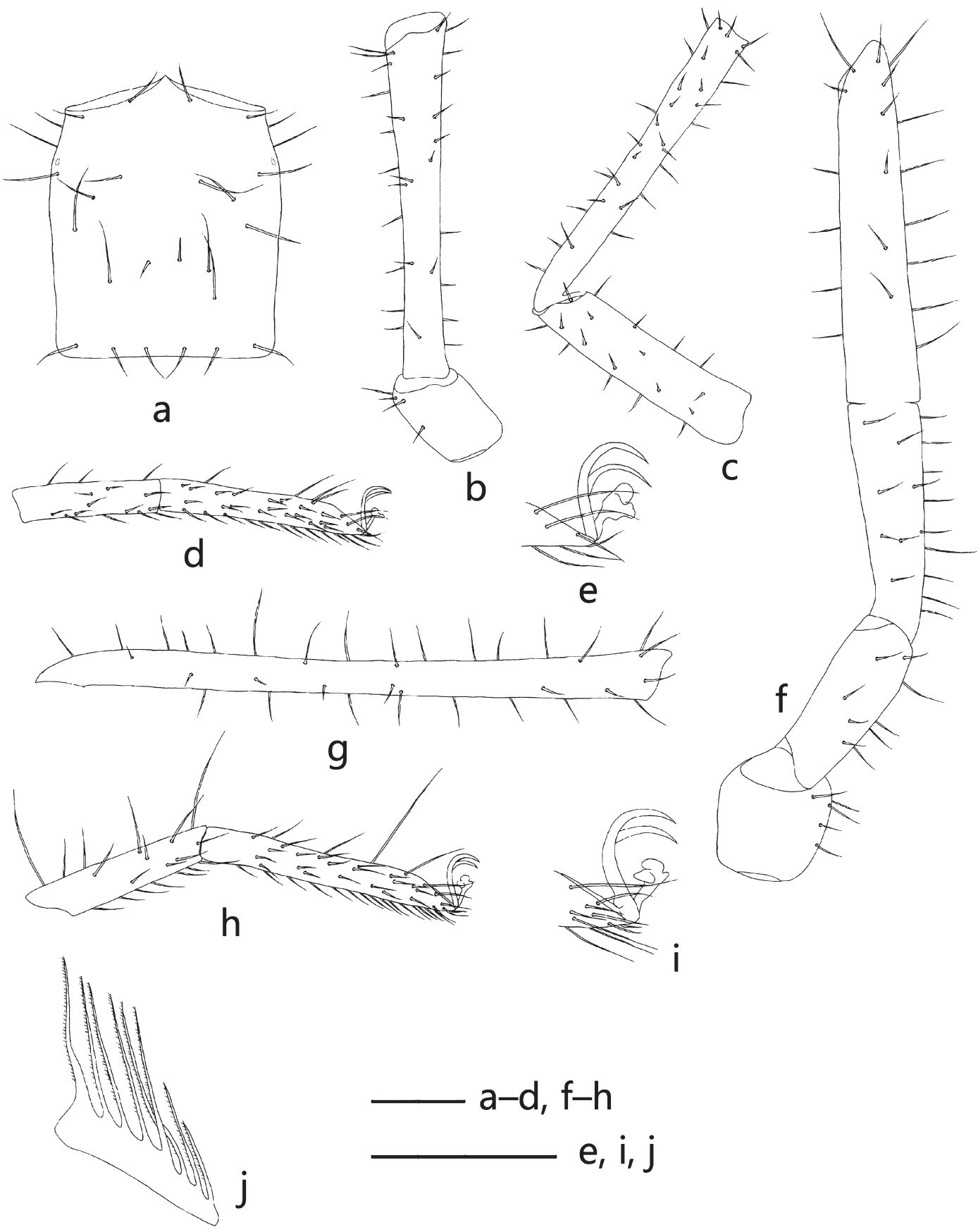

\section{$a-d, f-h$}

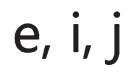

Fig. 1. Bisetocreagris xiaoensis sp. n., male holotype and paratype. - a. Carapace. - b-d. Left leg I, lateral view. - e. Apotele of left leg I, lateral view. $-\mathrm{f}-\mathrm{h}$. Right leg IV, lateral view. $-\mathrm{i}$. Apotele of left leg IV, lateral view. $-\mathrm{j}$.

Right rallum. Scale lines $0.2 \mathrm{~mm}$.

than in known species living in forests in leaf litter i.e. outside of caves, trochanter 2.81-3.40 times longer than broad, distal femur slightly enlarged, 6.92-7.61 times longer than broad, patella
7.84-10.36 times longer than broad, femur 0.930.98 times longer than patella, chela with pedicel 8.10-8.78 times longer than broad, hand with pedicel 3.71-3.96 times longer than broad; mov- 


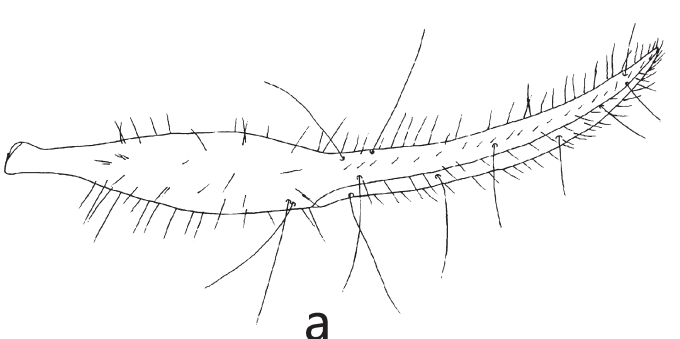

a

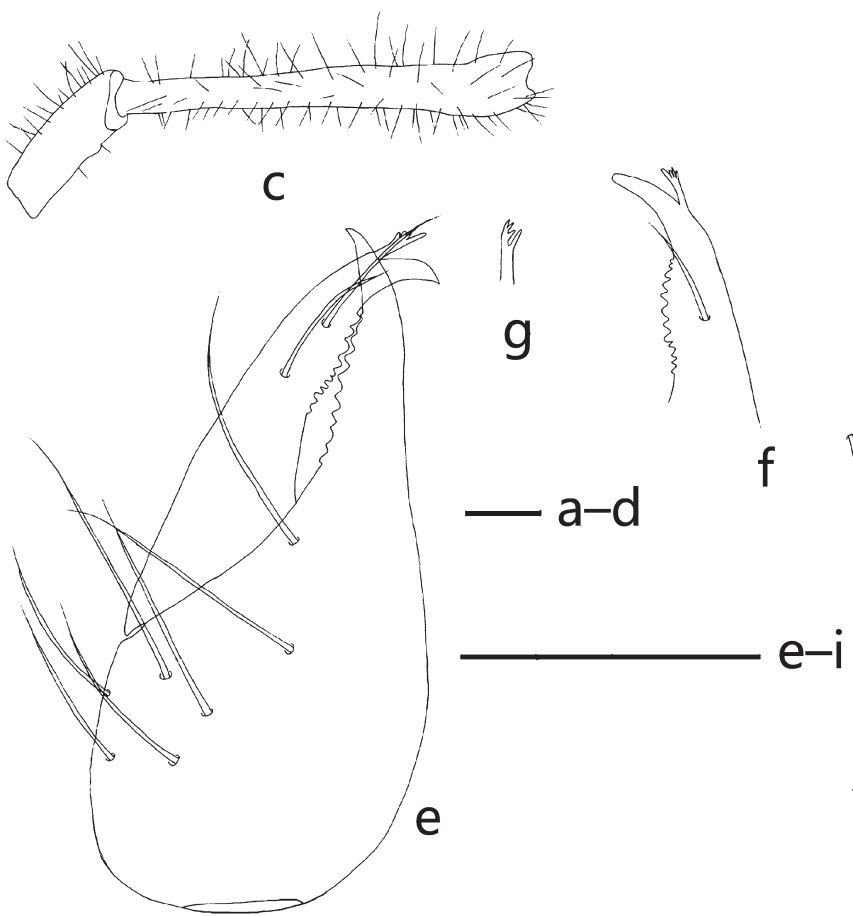

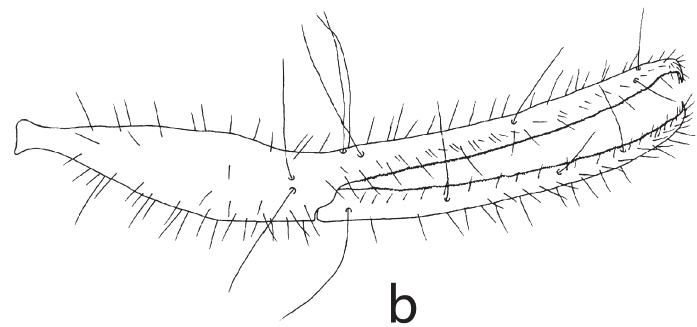

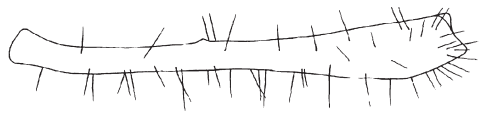

d

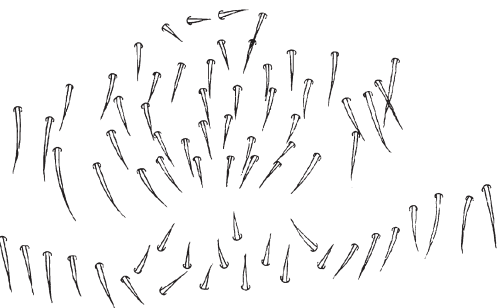

$\mathrm{h}$

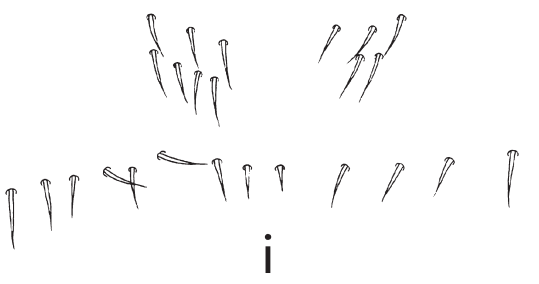

Fig. 2. Bisetocreagris xiaoensis sp. $\mathbf{n}$., male holotype (a-f, h), female (g, i). - a-b. Chela, antiaxial and dorsal view. - c-d. Pedipalp from trochanter to patella, antiaxial view. $-e$. Left chelicera. $-f$. Tip of movable finger of right chelicera, dorsal view. $-\mathrm{g}$. Female left cheliceral galea, dorsal view. $-\mathrm{h}-\mathrm{i}$. Male and female genital area. Scale lines $0.2 \mathrm{~mm}$.

able finger 1.14-1.23 longer than hand (with pedicel) length. Fixed finger with 163-171 small, cusped teeth, movable finger with 173-182 teeth, rounded in basal fifth of finger; venom duct in fixed finger, very short; 12 trichobothria $(8+4)$, et-it at same level near finger tip, est slightly distal of finger middle, $e b$-esb on distal lateral hand side, $s b$ on movable finger distinctly nearer to $b$ than to $s t$, st nearer to $t$ than to $s b$.

Legs (Fig. 1b-i): Typical, elongate. Fine granulation present on anterodorsal faces of femora I, IV and patella IV. Leg I: femur 6.818.64 times longer than deep and 1.37-1.55 times longer than patella, patella 5.41-6.17 times lon- ger than deep, tibia 8.31-12.44 times longer, basitarsus 4.05-5.92 times longer, telotarsus 6.00-6.67 times longer than deep, telotarsus 1.27-1.39 longer than basitarsus; leg IV: femur+patella 7.09-8.26 times longer than deep, femur shorter than patella, tibia 12.73-18.32 times longer than deep, basitarsus 3.91-5.40 times longer, with two tactile setae (basally, TS= $0.26-0.29$; distally, $\mathrm{TS}=0.29-0.31$ ), telotarsus 7.76-7.85 times longer than deep, with a tactile setae near middle $(\mathrm{TS}=0.41-0.43)$.

Measurements (in mm) (holotype and paratypes): Body length 5.25-5.42; carapace (length/ breadth) 1.44-1.46/1.16-1.17. Pedipalps: tro- 


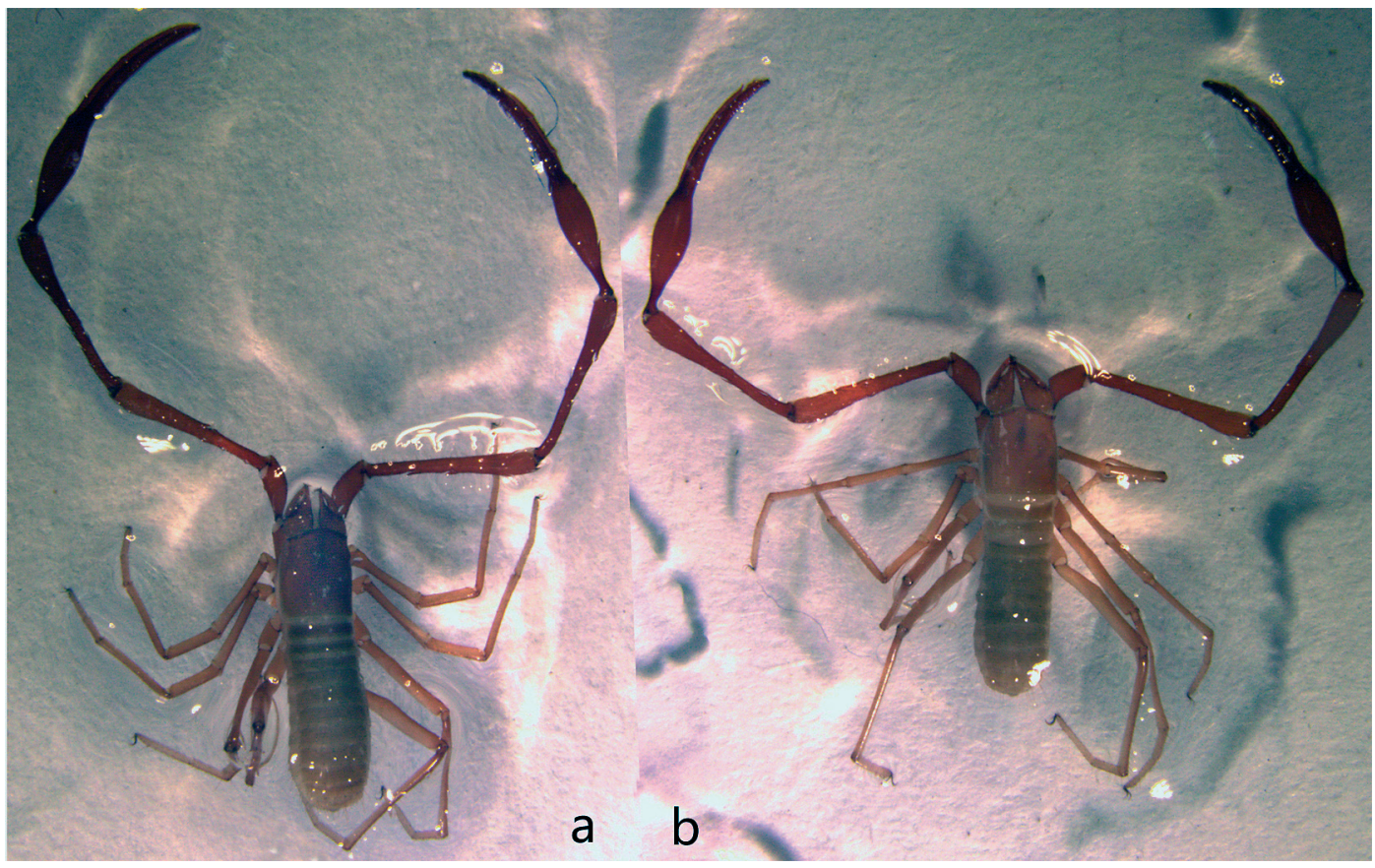

Fig. 3. Habitus of Bisetocreagris xiaoensis sp. n. - a. Male holotype (length $5.42 \mathrm{~mm}$ ). - b. Paratype female (length $5.31 \mathrm{~mm}$ ).

chanter 1.19-1.20/0.35-0.37, femur 2.752.80/0.34-0.37, patella 2.74-3.00/0.26-0.38, hand with pedicel 1.96-2.08/0.50-0.56, length of finger 2.42-2.48, length of chela 4.39 4.56/0.50-0.56. Leg I: femur 1.32-1.35/0.160.17 , patella $0.91-0.99 / 0.16-0.17$, tibia 1.29 $1.31 / 0.10-0.14$, basitarsus $0.54-0.59 / 0.09-0.10$, telotarsus $0.68-0.80 / 0.08-0.09$; leg IV: femur+patella $1.78-1.83 / 0.26-0.27$, tibia $2.01-$ $2.29 / 0.13-0.16$, basitarsus $0.52-0.78 / 0.13-0.14$, telotarsus 1.01-1.08/0.13-0.14.

Female (paratypes). Tergal chaetotaxy: 7:6:6:6:7:7:9:9:9:9:8 (2 tactile setae):4. Sternite III with an anteromedian groove, with one tiny seta on each margin, 21-22 long setae (1-2 medial discal setae)+3-4 suprastigmal setae. IVXII, 17-18:14:17-18:17:16:15-16:14:8 (2 lateral tactile setae):4. Manducatory process with 6 (5-6 on right side) marginal setae. Pedipalpal coxa with 7-8 setae. Genital operculum with 6/67 medial marginal setae (Fig. 2i). Cheliceral galea (Fig. 2g): a short slender transparent rod on left chelicera, divided in 2 main branches. Cheliceral rallum composed of 8 blades, distal one separated and with slightly expanded base. Measurements: Body length 5.31-6.53; carapace (length/ breadth) 1.55-1.58/1.23-1.24. Pedipalps: trochanter 1.29-1.34/0.40-0.41, femur 2.71$2.93 / 0.37-0.39$, patella $2.98-3.02 / 0.42-0.43$, hand with pedicel $2.17-2.23 / 0.62-0.63$, length of finger 2.47-2.62, length of chela 4.70 4.80/0.62-0.63. Leg I: femur 1.22-1.32/0.14 0.20 , patella $0.97-1.06 / 0.16-0.18$, tibia 0.99 $1.41 / 0.11-0.13$, basitarsus $0.46-0.66 / 0.11-0.13$, telotarsus $0.71-0.96 / 0.11-0.12$; leg IV: femur+patella $1.98-2.27 / 0.25-0.29$, tibia 1.89 2.03/0.15-0.18, basitarsus $0.49-0.64 / 0.14-0.15$, telotarsus 0.76-1.14/0.13-0.14.

Distribution. Yunnan Province, China.

Etymology. Latinized adjective, derived from the name of the locus typicus, Xiao cave.

Remarks. Checking all specimens of this new species revealed that only one chelicera of one male has two setae in its left movable finger, while other chelicera only has one seta. Beyond that difference, they have the same characteristics as other specimens. We believe that this is an unstable character. 


\section{Key to the known cave-dwelling species of the genus Bisetocreagris}

1. Carapace with eyes

- Carapace without eyes or eyespots

2. Carapace only with 2 (anterior) eyes with indistinct lense

- Carapace with 4 small eyes or eyespots 6

3. Eight setae on posterior margin of carapace; slender and shorter pedipalps, femur 4.4 times as long as broad (length $1.70 \mathrm{~mm}$ ), patella 3.1 times as long as broad (length $1.53 \mathrm{~mm}$ )

B. chuanensis Mahnert \& Li, 2016

- Either more or less than 8 setae on posterior margin of carapace; both pedipalpal femur (length $2.04-4.65 \mathrm{~mm}$ ) and patella (length $2.06-4.99 \mathrm{~mm}$ ) more than 4.7 times as long as broad

4. Carapace with 31 setae, 10 or 12 setae on posterior margin; pedipalpal femur length 4.65 $\mathrm{mm}$, patella length $4.99 \mathrm{~mm}$; genital operculum of male with about 80 short and thickened setae

B. juanxuae Mahnert \& Li, 2016

- Either more or less than 31 setae of carapace; both pedipalpal femur and patella shorter than $4.5 \mathrm{~mm}$; genital operculum of male with less than 80 setae

5. Cheliceral rallum with 10 pinnate setae, finger of both pedipalps with about 120 equal and closely situated teeth

B. chinacavernicola (Schawaller, 1995)

- Cheliceral rallum with 7-8 pinnate setae, fixed finger of pedipalps with 163-171 small, cusped teeth, movable finger with 173-175 teeth

B. xiaoensis sp. n. Li \& Liu

6. Anterior eyes with indistinct lense, posterior eyes indistinct and difficult to observe; distal pedipalps of dorsal and medial hand with fine granules; femur 5.8 times (length 1.92-2.10 $\mathrm{mm}$ ), patella 4.3-4.7 times (length 1.78-2.01 $\mathrm{mm}$ ) longer than broad

B. cavernarum Mahnert \& Li, 2016

- Four small eyes very distinct; trochanter of pedipalps with small dorsal hump, femur indistinctly granulate medially, femur 4.25 times (length $1.58 \mathrm{~mm}$ ), patella 2.7 times (length $1.35 \mathrm{~mm}$ ) longer than broad

B. martii (Mahnert, 2003)

7. 13 cheliceral rallum setae

B. titanium (Mahnert, 2003)

- Less than 13 cheliceral rallum setae

8. Carapace with 4 anterior and 6 posterior setae; tergites I-X with 6 setae, XI with 6 (of which 2 tactile) setae

B. scaurum (Mahnert, 2003)

- Carapace with 6 anterior and 7 posterior setae; tergites I-X with 7-9 (rarely 6 or 10), XI with 7 (of which 2 tactile) setae

B. baozinensis Mahnert \& Li, 2016

Acknowledgements. We are very grateful to Dr Mark Judson (Muséum national d'Histoire naturelle, Paris) for his careful guidance and Prof. Volker Mahnert (Muséum d'Histoire naturelle de la Ville de Genève) for his continuous support of our study. We also thank Prof. Juan A. Zaragoza (Departamento de Ecología, Facultad de Ciencias, Universidad de Alicante. Spain) and an anonymous reviewer for improving the manuscript. This study was supported by the Innovation Fund for Graduate Students of Chongqing (CYB17062).

\section{References}

Chamberlin, J. C. 1931: The arachnid order Chelonethida. - Stanford University Publications, University Series, Biological Sciences 7(1): 1-284.

Guo, X. B. \& Zhang, F. 2017: Two new species of Bisetocreagris Ćurčić, 1983 (Pseudoscorpiones: Neobisiidae) from China. - Acta Zoologica Academiae Scientiarum Hungaricae 63(1): 71-82.

Harvey, M. S. 1992: The phylogeny and classification of the Pseudoscorpionida (Chelicerata: Arachnida). Invertebrate Taxonomy 6: 1373-1435.

Harvey, M. S. 2013: Pseudoscorpions of the World. Version 3.0. - Western Australian Museum, Perth. http://www.museum.wa.gov.au/catalogues-beta/ pseudoscorpions (site visited on 25 April, 2017).

Judson, M. L. I. 2007: A new and endangered species of the pseudoscorpion genus Lagynochthonius from a cave in Vietnam, with notes on chelal morphology and the composition of the Tyrannochthoniini (Arachnida, Chelonethi, Chthoniidae). - Zootaxa 1627: 53-68.

Mahnert, V. \& Li, Y. C. 2016: Cave-inhabiting Neobisiidae (Arachnida: Pseudoscorpions) from China, with description of four new species of Bisetocreagris Ćurčić. — Revue Suisse de Zoologie 123(2): 259-268. 